\title{
Terapia de casos refratários
}

\section{Geraldina Porto Witter - Universidade Camilo Castelo Branco e Academia Paulista de Psicologia, São Paulo, Brasil}

McKay, D., Taylor, S. \& Abramwitz, J. S. (Orgs.). (2011). Cognitive Behavioral Therapy and refratory cases: Turning failure into success. Washington, DC, US: American Psychological Association, xii+432 p. Também disponível em http://psychet.apa.org/books/12070/001.pdf.

Em decorrência de diversas variáveis, nem sempre a psicoterapia alcança os objetivos desejados, a despeito das tentativas e do número de vezes em que a pessoa com problemas comportamentais busca solução para os mesmos. Tais casos são designados como refratários. O livro aqui resenhado apresenta estratégias bem sucedidas desenvolvidas no enfoque de Terapia Comportamental Cognitiva, hoje a mais atuante e com maior sustentabilidade em evidências.

Os autores são doutores e pesquisadores conhecidos e organizaram a obra com o apoio da American Psychological Association (APA), contando também com a colaboração de outros autores conhecidos. São 18 capítulos, cada um focalizando um histórico de difícil solução e que, com o devido atendimento comportamental cognitivo, pode se transformar em êxito. Os problemas focados pelos diversos autores foram: pânico com agorafobia, respostas limitadas ao tratamento, ansiedade social, comportamento obsessivo-compulsivo, ansiedade generalizada, estresse pós-traumático, distúrbios alimentares, depressão, uso de substâncias, controle de impulso, problemas sexuais, insônia, cólera, hipocondria e ansiedade em relação à saúde, personalidade limítrofe, paralisias, comportamento antissocial e psicopatológico.

O primeiro dos 18 capítulos foi escrito pelos organizadores do livro e fornece uma base históricoconceitual e de evidências que por si só justificam a elaboração do livro. Lembram avanços já históricos de eventos e exigências que passaram a ser feitas desde os anos 90 em relação aos protocolos de psicoterapia que apresentaram evidências do efeito de tratamento, lembrando que experimentos com caso único são chamados provavelmente eficazes e são úteis quando não testados a ainda ou antes é uma proposta em experiência. Muitos tratamentos com adequados suportes empíricos estão disponíveis na Terapia Comportamental ou Cognitivo-Comportamental (CBT), mas nem sempre estão sendo usadas nas clínicas. Entre as variáveis do cliente que não levam a ter êxito no tratamento destaca algumas para as quais a CBT tem recursos:

\footnotetext{
${ }^{1}$ Endereço para correspondência:

Av. Pedroso de Morais, 144, ap. 302 - Pinheiros - 05420-000 - São Paulo-SP

E- mail: gwitter@uol.com.br
}

gerenciamento cognitivo ou intelectual baixo, conhecimento do problema pelo paciente, comorbidade e diagnóstico. Também destaca que fatores do terapeuta podem influir. Faz um sumário contrastivo do tratamento com base empírica e a prática com apoio empírico e salienta que a análise das falhas pode ser um bom aprendizado no desenvolvimento de intervenções mais eficazes e no refinamento de práticas empiricamente sustentadas.

O segundo capítulo é uma ampliação do referencial teórico-conceitual e foi escrito por Federici, Rowa e Antony. Os autores tratam do ajustamento da CBT quando o paciente não responde ou responde pouco no processo psicoterapêutico. Retomam os fatores selecionados ao cliente, ao terapeuta $\mathrm{e}$ ao diagnóstico e formas de mudar a CBT para transformar o fracasso em êxito, tais como: rever a base, modificar o conteúdo das sessões, enfatizar as expectativas, as tarefas complementares feitas em casa, a mudança nas liberações e o atendimento das comorbidades. Apresentam uma síntese de novas maneiras de atuação para obter os resultados esperados. As estratégias focam: motivação, aceitação da internação, controle emocional, técnicas para treino de capacidades específicas, busca da perfeição. Dentre variáveis a mudar no comportamento do psicoterapeuta citam: trabalhar a aliança, mudar expectativas, interferências comportamentais.

Cada um dos capítulos seguintes enfoca um dos problemas arrolados no início desta resenha, todos escritos por especialistas e produtores científicos que atuam na área. $\mathrm{Na}$ impossibilidade de descrever todos no espaço aqui disponível optou-se por apresentar um capítulo para que o leitor tenha uma ideia da estrutura que é a mesma norteadora dos demais temas.

O capítulo sobre Pânico com Agorafobia foi elaborado por Magaro e Craske. Começa com uma breve revisão conceitual e da história do problema, retornando aos clássicos da área até chegar às contingências atuais no atendimento de pessoas com pânico. Revisões recentes de pesquisas na área evidenciaram que a CBT apresenta dados com êxito sustentado em evidências no tratamento do tema. Descrevem a relevância do distúrbio do pânico, sua definição e a importância de se obter a mudança comportamental para o bem-estar do paciente e sua 
integração familiar no trabalho e na sociedade. Relatam os avanços na CBT para obter êxito no tratamento, indicando os procedimentos, êxito e fatores associados, bem como os problemas de comorbidade de humor, médicas, uso de drogas etc., e ainda os sinais de recuperação a que se deve estar atento. Apresentam um estudo de caso bem descrito como exemplo de intervenção psicoterapêutica. Nas conclusões, destacam o fato de a CBT ser considerada a primeira linha eficiente no tratamento do pânico e da agorafobia, embora ainda haja muito que se pesquisar para saber as razões de alguns pacientes não responderem ao tratamento como o esperado e sugestões para mudar este quadro. Há boas estratégias com evidências conhecidas, mas há necessidade de mais pesquisas, especialmente na presença de comorbidades associada, ao problema enfocado.

Em todos os capítulos a bibliografia é principalmente constituída por artigos de revistas e algum livro ou texto histórico. É de alto nível, pertinente e atualizada. São textos muito úteis para terapeutas que atendem pacientes com os problemas enfocados, bem como para supervisores de estágio e pesquisadores que estejam interessados nos tópicos apresentados em cada capítulo.

Os artigos são de leitura estimulante e apresentam novos horizontes e possibilidades de atendimento eficaz de problemas que atingem muitas pessoas. São também contribuições efetivas para a atualização profissional e a capacitação de recursos humanos.

Geraldina Porto Witter é doutora em Ciências, livre-docente em Psicologia Escolar; professora emérita da UFPa, do UNIPÊ e da UNICASTELO, coordenadora da Extensão e do Comitê de Ética em Pesquisa da UNICASTELO e membro da Academia Paulista de Psicologia 